\title{
Carbon Monoxide Poisoning
}

\author{
Maj Gen SR Mehta, vsm*, Lt Col S Das ${ }^{+}$, Lt Col SK Singh"
}

MJAFI 2007; 63 : 362-365

Key Words : Carbon monoxide poisoning; Carboxyhemoglobin

\section{Introduction}

$\mathrm{C}$ arbon monoxide $(\mathrm{CO})$ is a nonirritating colourless, odourless gas produced by incomplete burning of carbon containing fossil fuels. The normal concentration in atmosphere is less than $0.001 \%$ and a concentration of $0.1 \%$ can be lethal. It causes thousands of uncalled for deaths each year. Patients who survive the initial poisoning can develop delayed neurologic dysfunction, which occurs in $14-40 \%$ of serious cases. At present $\mathrm{CO}$ is one of the commonly encountered poison in our environment and a leading cause of poisoning world wide [1-3]. Poisoning can be acute, subacute and chronic [4].

\section{Sources of Carbon Monoxide}

The human body produces carbon monoxide as a byproduct of hemoglobin degradation, resulting in baseline carboxyhemoglobin $(\mathrm{COHb})$ saturation of $1-3 \%$ in non-smokers, which increases to $10-15 \%$ amongst heavy smokers. A smoker is exposed to 400 to 500 ppm of CO while actively smoking [1,2]. According to a ten year review of carbon monoxide related deaths more than half of unintentional deaths were caused by motor vehicle exhaust [1]. Burning of charcoal, wood, kerosene, or natural gas for heating and cooking also produces carbon monoxide [5]. In army setting poisoning is usually seen in high-altitude areas where unwary soldiers often sleep in closed tents with burning bhukharis (charcoal/kerosene) kept inside [6].

Carbon monoxide can occur in the presence of other toxins, complicating management. It is a major contributor in the thousands of smoke inhalation deaths that occur each year [1]. People who work with methylene chloride as paint stripper, can be poisoned because the fumes are readily absorbed and converted to $\mathrm{CO}$ in the liver [4]. In such cases, peak $\mathrm{COHb}$ levels may be delayed and prolonged because of on going production of $\mathrm{CO}$ from liver.

\section{Toxicity}

The amount of $\mathrm{CO}$ absorbed by the body depends on minute ventilation, duration of exposure and concentration of $\mathrm{CO}$ in the environment. Carbon monoxide quickly binds with hemoglobin with an affinity greater than that of oxygen to form $\mathrm{COHb}$. The resulting decrease in arterial oxygen content and shift of the oxyhemoglobin dissociation curve to the left explains the acute hypoxic symptoms (primarily neurologic and cardiac) seen in patients with acute poisoning [5]. But the toxic effects of $\mathrm{CO}$ cannot be explained by these processes alone, as $\mathrm{COHb}$ levels do not correlate well with symptoms, outcome or the phenomenon of delayed neurologic sequelae [2,7].

Research suggests that the intracellular uptake of carbon monoxide is an important mechanism for neurologic damage. When carbon monoxide binds to cytochrome oxidase, it causes mitochondrial dysfunction resulting into oxidative stress related damage [8]. The release of nitric oxide from platelets and endothelial cells, which forms the free radical peroxynitrite, can further inactivate mitochondrial enzymes and damage the vascular endothelium of the brain [9]. The end result is lipid peroxidation of the brain, which starts during recovery from carbon monoxide poisoning. With reperfusion of the brain, leukocyte adhesion and the subsequent release of destructive enzymes and excitatory amino acids all amplify the initial oxidative injury [1012]. The net result is cognitive defects, particularly in memory and learning with movement disorders that may not appear for days following the initial poisoning. Carbon monoxide exposure has an especially deleterious effect on pregnant women, because of the greater sensitivity of the foetus to the harmful effects of the gas. The final $\mathrm{COHb}$ levels in the foetus significantly exceeds the level in the mother [13]. The excessive left shift of foetal $\mathrm{COHb}$ curve makes tissue hypoxia more severe by

"Senior Consultant (Medicine), +Jt Dir AFMS (Pens), "SO to Senior Consultant (Medicine), O/o DGAFMS, Ministry of Defence,'M' Block, New Delhi-110001.

Received : 09.03.2007; Accepted : 11.08.2007 
releasing less oxygen to the foetal tissues [14]. Although the teratogenicity of $\mathrm{CO}$ is controversial, the risk of foetal injury is increased [15-17]. Once CO exposure is discontinued, dissociation of $\mathrm{COHb}$ occurs and $\mathrm{CO}$ is excreted through the lungs. At atmospheric pressure, the $\mathrm{COHb}$ half-life is four to six hours which decreases to $40-80$ minutes on breathing $100 \%$ oxygen.

\section{Clinical Manifestations}

Clinical manifestations of acute $\mathrm{CO}$ poisoning can be vague and may closely mimic various nonspecific viral illnesses. CO poisoning usually affects many people at the same time. The acute symptoms of $\mathrm{CO}$ poisoning are reflected in the susceptibility of the brain and heart to hypoxia. Initially, patients may complain of headache, dizziness, nausea, emotional liability, confusion, impaired judgment, clumsiness and syncope ]7, 18,19].Vomiting may be the only presenting symptom in infants and may be misdiagnosed as gastroenteritis. Coma or seizures can occur in patients with prolonged $\mathrm{CO}$ exposure [2]. Elderly patients, especially those with coronary artery disease, may have accompanying myocardial ischaemia, which may result in frank myocardial infarction [12]. The clinical manifestations are depicted in Table 1.

Prolonged exposures resulting in coma or altered mental status, may be accompanied by retinal hemorrhages and lactic acidosis [7]. Myonecrosis can occur but it rarely leads to compartment syndrome or renal failure. Cherry-red skin colour associated with severe carbon monoxide poisoning, is seen in only $2-3 \%$ of symptomatic cases [13]. Skin may develop erythematous lesions and bulla especially over bony prominences. Severe poisoning often leads to hypotension and pulmonary oedema with the former being the most reliable marker of overall prognosis. The clinical features are depicted in Table 2.

\section{Persistent and Delayed Effects}

Patients can successfully recover from acute $\mathrm{CO}$ poisoning, only to return days later with serious neurological problems, ranging from subtle cognitive deficits (apparent on neuropsychological testing), to gross

Table 1

Levels of $\mathrm{COHb}$ and clinical manifestations

\begin{tabular}{|c|c|}
\hline $\begin{array}{l}\text { Blood } \mathrm{COHb} \\
\text { concentration (\%) }\end{array}$ & Clinical manifestations \\
\hline $15-20$ & Mild headache, easy fatigability \\
\hline $20-30$ & $\begin{array}{l}\text { Pounding headache, impaired motor } \\
\text { dexterity, blurring of vision, irritability }\end{array}$ \\
\hline $30-40$ & $\begin{array}{l}\text { Severe muscle weakness, nausea, } \\
\text { vomiting, mental confusion or delirium }\end{array}$ \\
\hline $40-50$ & Tachycardia, cardiac irritability \\
\hline $50-60$ & Seizures, respiratory insufficiency \\
\hline$>60-70$ & Coma, respiratory failure, death \\
\hline
\end{tabular}

incapacitating movement disorders, resulting from carbon monoxide's predilection for basal ganglia [14]. Within a day of high $\mathrm{CO}$ exposure, neuroimaging can show decreased density in the central white matter and globus pallidus. Autopsies have shown involvement of cerebral cortex, hippocampus, cerebellum, and substantia nigra.

Neurologic sequelae may be evident immediately or may occur after a lucid interval of up to three weeks. The incidence of such sequelae can be as high as $40 \%$ (for memory impairment), and they may persist for more than a year. Children may present with behavioural or learning problems, while the elderly appear to be more susceptible to devastating consequences [20,21]. The development of neurologic sequelae cannot be reliably predicted, however, most cases are associated with loss of consciousness in the acute phase of intoxication [2]. The standard CO neuropsychological screen battery helps in objective evaluation of such patients.

\section{Chronic CO Poisoning}

The symptoms of low level chronic $\mathrm{CO}$ intoxication are non specific and unlikely to arouse suspicion of $\mathrm{CO}$ as the cause. It can also exacerbate the preexisting diseases like ischaemic heart disease or dementia [22] . Patients present with bizarre behavioural abnormalities, declining intellect, memory disturbances, chronic cough or diarrhoea. The condition is often misdiagnosed as chronic fatigue syndrome, a viral, bacterial, pulmonary, gastrointestinal infection or immune deficiency. Patients may occasionally present with polycythemia or increased hematocrit. $\mathrm{COHb}$ is usually not excessively elevated.

Table 2

\begin{tabular}{|c|c|c|}
\hline Method & Advantages & Disadvantages \\
\hline $\begin{array}{l}\text { Spectrophotometric } \\
\text { analysis }\end{array}$ & $\begin{array}{l}\text { Quantitative assessment } \\
\text { Rapid } \\
\text { Guide for therapy }\end{array}$ & $\begin{array}{l}\text { Delay in analysis } \\
\text { may lead to } \\
\text { spuriously normal } \\
\text { COHb levels } \\
\text { Costly and not } \\
\text { readily available }\end{array}$ \\
\hline $\begin{array}{l}\text { Kunkel's test } \\
\text { ( } 5 \text { to } 6 \text { drops of } \\
3 \% \text { tannic acid } \\
\text { added to patient's } \\
\text { diluted blood gives } \\
\text { a persistent crimson } \\
\text { red coagulum) }\end{array}$ & Rapid field test & $\begin{array}{l}\text { Only qualitative } \\
\text { analysis }\end{array}$ \\
\hline Pulse oxymetry & $\begin{array}{l}\text { Non invasive } \\
\text { bed side test }\end{array}$ & $\begin{array}{l}\text { Unreliable because } \\
\text { it grossly over } \\
\text { estimates oxygen } \\
\text { saturation in the } \\
\text { presence of } \mathrm{COHb}\end{array}$ \\
\hline Arterial blood & $\begin{array}{l}\text { Useful to confirm } \\
\text { lactic acidosis, which } \\
\text { is a marker of } \\
\text { prolonged, serious } \\
\text { exposure to } \\
\text { carbon monoxide }\end{array}$ & $\begin{array}{l}\text { Measures dissolved } \\
\text { oxygen and thus } \\
\text { overestimates the } \\
\text { true oxygen } \\
\text { saturation of } \\
\text { hemoglobin }\end{array}$ \\
\hline
\end{tabular}




\section{Diagnosis}

Physicians should be alert for the symptoms of carbon monoxide poisoning, especially during the winter, when risk of continued, prolonged exposures may be greater. Patients who present with flu-like symptoms (i.e., headache, nausea, dizziness) should be questioned about the use of gas or oil based heating appliances at home or work . The same symptoms occurring in housemates are also a warning sign of environmental exposure. Various clinical features for evaluation of such cases are shown in Table 3. A hand held breath analyzer can be used to quickly rule out carbon monoxide poisoning; however, the incidental presence of ethanol can result in a false-positive reading. Comatose patients can be monitored for rhabdomyolysis by measuring creatine kinase (CK) levels.

A brain computed tomograpghy (CT) scan may be normal in early stages or show signs of cerebral oedema. Later on CT may show symmetrical bilateral hypodensities of the basal ganglia, particularly of the globus pallidus and substantia nigra. The other abnormalities may be subcortical white matter hypodensities, cerebral cortical lesions, hippocampal lesions, and loss of gray-white differentiation. The electro encephalogram usually demonstrates diffuse slowing which is of little prognostic value. Single photon emission computed tomography (SPECT) has also been used in $\mathrm{CO}$ poisoning cases.

\section{Treatment}

The initial treatment of patients with symptomatic carbon monoxide poisoning is relatively straightforward. A non-re-breather mask supplies $100 \%$ oxygen to quickly clear $\mathrm{COHb}$ from the blood and this therapy reduces the half-life of $\mathrm{COHb}$ from about 4-5 hours to one hour [4]. Oxygenation at a peripheral setup can be given with a simple oro-nasal plastic mask at a flow rate of 6 to 10 litres/minute which gives oxygen concentration of about $35-50 \%$. Oxygen delivery with face mask with reservoir

Table 3

$\begin{array}{lcc}\text { Clinical features } & \begin{array}{c}\text { Mehta et al [6] } \\ (\mathrm{n}=25) \% \text { of patient }\end{array} & \begin{array}{c}\text { Pooled data Ely et al[7], } \\ \text { Myers et al [18] and } \\ \text { Burney [19] }(\mathrm{n}=196) \\ \% \text { of patient }\end{array} \\ \begin{array}{l}\text { Drowsiness and/ } \\ \text { or confusion }\end{array} & 48 & 43 \\ \text { Coma } & 24 & 6 \\ \text { Hemiparesis } & 24 & 6 \\ \begin{array}{l}\text { Seizures } \\ \text { Angina pectoris }\end{array} & 12 & - \\ \begin{array}{l}\text { Dyspnoea/ } \\ \text { tachypnoea }\end{array} & 8 & 9 \\ \text { Tachycardia } & 80 & 40 \\ \text { Cherry red skin } & 64 & - \\ & 24 & -\end{array}$

bag and a flow rate of 8-10 litres/ minute provides an oxygen concentration of about $70-80 \%$. Face mask with reservoir bag and directional valve with flow rate of 10 15 litres/minute achieves oxygen concentration of about 90-95\%. Hypotension is treated with fluids and vasopressors. In confused patients, a finger stick glucose test is essential to rule out hypoglycemia. Occasional seizure may require administration of benzodiazepines. Patients with suspected coronary artery disease may benefit from an electrocardiogram, CK testing, and therapy for angina. Kidneys can be protected from rhabdomyolysis with aggressive hydration to increase urination. The criteria for intensive care admission are shown in Table 4.

\section{Hyperbaric Oxygen Therapy}

Hyperbaric oxygen therapy (HBO) involves enclosing the patient in a pressure chamber and administering $100 \%$ oxygen at a pressure greater than 1 atmosphere absolute (ATA). HBO at 2.5 ATA reduces the half-life of $\mathrm{COHb}$ to about 20 minutes. $\mathrm{HBO}$ has been used in CO poisoning management since 1962 [22]. In addition to accelerated rate of $\mathrm{CO}$ elimination from hemoglobin, removal from intracellular binding sites is also enhanced by HBO treatment. The timely administration of HBO prevents neuronal injury, prevents delayed neuropsychological sequelae and terminates the biochemical deterioration. [21-23]. Suggested indications for $\mathrm{HBO}$ therapy in $\mathrm{CO}$ poisoning are given in Table 5. Adjunctive therapy such as administration of

Table 4

Criteria for admission and prolonged observation

1. Loss of consciousness

2. Neurological deficit at any time

3. Clinical or electrocardiographic signs of cardiac compromise

4. Metabolic acidosis

5. Abnormal chest radiograph

6. $\mathrm{COHb}$ level $>25 \%, \mathrm{COHb}$ level $>15 \%$ with a history of cardiac disease or $>10 \%$ in a pregnant patient

7. $\mathrm{PO}_{2}<60 \mathrm{~mm} \mathrm{Hg}$

Table 5

Indications for $\mathrm{HBO}$ therapy in $\mathrm{CO}$ poisoning

1. Comatose patients

2. Any period of unconsciousness

3. Any abnormal score on the Carbon Monoxide Neuropsychological Screening Battery

4. Patients with $\mathrm{COHb}$ levels $>40 \%$

5. Cardiovascular involvement (chest pain, ECG changes, arrhythmias)

6. History of ischaemic heart disease and $\mathrm{COHb}$ levels $>15 \%$

7. Pregnant patients with $\mathrm{COHb}$ levels $>15 \%$

8. Patients who do not respond to $100 \%$ oxygen after $4-6$ hours

9. Patients with recurrent symptoms up to three weeks after exposure 
corticosteroids, mannitol, hypothermia and hyperventilation has been recommended in serious cases of $\mathrm{CO}$ poisoning but their benefit has not been proved.

\section{Prevention}

Prevention requires public education on the safe operation of appliances, heaters, fireplaces and internal combustion engines. Increased awareness amongst soldiers posted to cold /high altitude areas about the dangers of using sigris and bhukharis in enclosed places like tents/bashas/barracks/rooms will go a long way in preventing $\mathrm{CO}$ poisoning and deaths. Burn victims, with evidence of smoke inhalation from an enclosed fire, should undergo testing for $\mathrm{COHb}$ levels. During winters, $\mathrm{CO}$ poisoning should be suspected in patients presenting with flu-like symptoms (e.g., headache, dizziness, nausea), which they may not attribute to a faulty furnace or other heating sources.

Carbon monoxide detectors with alarms can improve home safety and their use is recommended by various safety organizations [24-26].

\section{Conflicts of Interest}

None identified

\section{References}

1. Cobb N, Etzl RA. Unintentional carbon monoxide related deaths in United States. JAMA1991; 266:659-63.

2. National Center for Health Statistics. Vital statistics of the United States, 1988. Washington, DC: Government Printing Office, 1991: 89-1102.

3. Raub JA, Mathieu-Nolf, Hampson NB, Thom SR, et al. Carbon monoxide poisoning-a public health perspective. Toxicology 2000: 145:1-14.

4. Grace TW, Platt FW. Sub acute poisoning. JAMA 1981; 246:1698-700.

5. Meredith T, Vale A. Carbon monoxide poisoning. BMJ 1988; 296:77-9.

6. Mehta SR, Niyogi M, Kasthuri AS, et al. Carbon monoxide poisoning. J of Assoc of Physicians of India 2001; 49:622-5.

7. Ely EW. Moorehead B, Haponik EF. Warehouse workers' headache: emergency evaluation and management of 30 patients with carbon monoxide poisoning. Am J Med 1995; 98:145-55.

8. Baker SP, O’Neill B, Ginsburg MJ, Li G. The injury fact book. $2^{\text {nd }}$ ed. New York: Oxford University Press, 1992; 273-4.

9. Deaths from motor vehicle related unintentional carbon monoxide poisoning-Colorado, 1996, and United States, 19791992. Morb Mortal Wkly Rep1996; 45:1029-32.

10. Coburn RF. Carbon Monoxide toxicity. In: Farhi LE, Tenney SM, editors. Handbook of physiology. Gas exchange. Bethesda, Md. American physiological society, 1987:439-56.

11. Zhiang J, Piantadosi CA. Mitochondrial oxidative stress after carbon monoxide hypoxia in the rat brain. J Clin Invest 1992; 90:1193-9.

12. Thom SR. Dehydrogenase conversion to oxidase and lipid peroxidation in brain after carbon monoxide poisoning. J Appl Physiol 1992; 73:1584-9.

13. Longo LD, Hill EP. Carbon monoxide uptake and elimination in fetal and maternal sheep. Am J Phsiol 1977; 232:324-30

14. Farrow JR, Davis GJ, Roy TM, McCloud LC, Nichols GR II. Fetal death due to nonlethal maternal carbonmonoxide poisoning. J Forensic Sci 1990; 35:1448-52.

15. Norman CA, Halton DM. Is carbon monoxide a workplace teratogen? A review and evaluation of the literature. Ann Occup Hyg 1990; 34:335-47.

16. Ginsberg MD, Myers RF. Fetal brain injury after maternal carbon monoxide intoxication: clinical and neuropathological aspects. Neurology1976; 26:15-23.

17. Robkin MA. Carbon monoxide and the embryo. Int J Dev Biol 1997; 11:283-9.

18. Myers RAM, Synder SK. Subacute sequelae of carbon monoxide poisoning. Ann Emerg Med 1985;14:1163-7.

19. Burney RE. Mass carbon monoxide poisoning - 184 victims. Ann Emerg Med 1982;11: 394-9.

20. Cho IS. Delayed neurologic sequelae in carbon monoxide intoxication. Arch Neurol 1983; 40:433-5.

21. Hark IK, Kennedy PGE. Neurological manifestation of carbon monoxide poisoning. Postgrad Med J 1998; 64:213-6.

22. Harper A, Croft Baker J. Carbon Monoxide Poisoning. Age and Ageing 2004; 33:105-9.

23. Ernst A, Zibrak JD. Carbon monoxide poisoning. N Engl J Med 1998; 339: 1603-8.

24. Remick R, Miles J. Carbon monoxide poisoning: neurological and psychiatric sequelae. Can Med Assoc J 1997; 117:654-6.

25. Tomaszewski C. Carbon monoxide poisoning: Early awareness and intervention can save lives. Postgraduate Medicine 1999; 105: 345-54.

26. Kao LW, Nanagas KA. Carbon monoxide poisoning. Med Clin N Am 2005; 89:1161-94. 